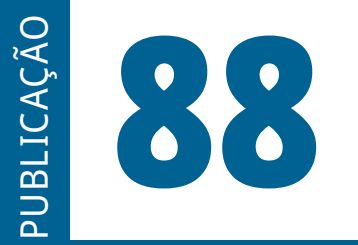

ISSN: 0101-9562

ISSN ELETRÔNICO: 2177-7055

SEQÜÊNCIA

Publicação do

Estudos jurídicos

e políticos

Programa de Pós-Graduação em Direito da UFSC

VOLUME 42 - ANO 2021 
SEQUÊNCIA - ESTUDOS JURÍDICOS E POLÍTICOS é uma publicação temática e de periodicidade quadrimestral, editada pelo Programa de Pós-Graduação Stricto Sensu em Direito da Universidade Federal de Santa Catarina - UFSC.

SEQUÊNCIA - ESTUDOS JURÍDICOS E POLÍTICOS is a thematic publication, printed every four months, edited by the Program in law of the Federal University of Santa Catarina - UFSC.

Versão eletrônica: http://www.periodicos.ufsc.br/index.php/sequencia

A publicação é indexada nas seguintes bases de dados e diretórios/

The Publication is indexed in the following databases and directories:

Base OJS

Base PKP

CCN (Catálogo Coletivo Nacional)

Dialnet

DOAJ (Directory of Open Access Journals)

EBSCOhost

Genamics Journalseek

ICAP (Indexação Compartilhada de Artigos de Periódicos)

Latindex

LivRe!

OJS
PKP
Portal de Periódicos UFSC
Portal do SEER
ProQuest
SciELO
Sherpa/Romeo
Sumarios.org
ULRICH'S
vLex

Ficha catalográfica

Seqüência: Estudos jurídicos e políticos. Universidade Federal de Santa Catarina.

Programa de Pós-Graduação em Direito. n.1 (janeiro 1980)-.

Florianópolis: Fundação José Boiteux. 1980-.

Publicação contínua

Resumo em português e inglês

Versão impressa ISSN 0101-9562

Versão on-line ISSN 2177-7055

1. Ciência jurídica. 2. Teoria política. 3. Filosoia do direito. 4. Periódicos.

I. Universidade Federal de Santa Catarina. Programa de Pós-graduação em

Direito

CDU 34(05)

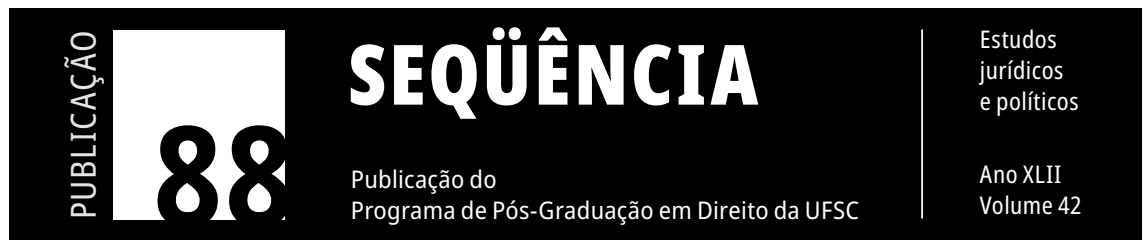




\title{
Diálogo institucional e democracia: das experiências do Canadá e da África do Sul para o Brasil ${ }^{1}$
}

\section{Institutional dialogue and democracy: the experience of Canada and South Africa to Brazil}

\author{
Gianfranco Faggin Mastro Andréa \\ Universidade Presbiteriana Mackenzie, São Paulo, Brasil \\ José Carlos Francisco \\ Universidade Presbiteriana Mackenzie, São Paulo, Brasil \\ Wagner Wilson Deiró Gundim \\ Faculdade de Direito da Universidade \\ Anhembi Morumbi, São Paulo, Brasil
}

RESUMO: O presente artigo tem como objetivo geral apresentar diálogos institucionais como mecanismo de aprimoramento da fórmula democrática, ressaltando a necessidade do estabelecimento de uma relação dialógica entre poderes estatais, e como objetivo específico expor as experiências do Canadá e da África do Sul, potencialmente úteis para o Brasil. Inicialmente, o estudo aborda e delimita o conceito de diálogo institucional para então demonstrar a possibilidade de uma relação dialógica entre política e direito no âmbito da construção do processo decisional e da interpretação constitucional. Na sequência, investiga a sua experiência tanto no arranjo institucional canadense, como nos recentes posicionamentos da Corte Constitucional da África do Sul. Ao final, conclui que diálogos institucionais

1 O presente artigo é fruto dos debates e reflexões gestadas no Grupo de Pesquisa Cidadania, Constituição e Estado Democrático de Direito, vinculado ao Programa de Pós-Graduação de Mestrado e Doutorado em Direito Político e Econômico da Universidade Presbiteriana Mackenzie. 
são instrumentos facilitadores para a superação de bloqueios porque podem criar interlocução qualificada entre os poderes estatais e também com segmentos da sociedade, recompondo fissuras na separação dos poderes muitas vezes gerada pelo modelo juriscêntrico de solução de judicializações de políticas públicas.

Palavras-Chave: Diálogos Institucionais - Separação de Poderes - Relação Dialógica - Arranjos Institucionais.

ABSTRACT: The present article has as background to present the theory of institutional dialogues as a pretended mechanism of improvement of the democratic formula, emphasizing the need to establish a dialogical relationship between the State powers, and as a specific goal expose the experiences of Canada and South Africa's potentially useful for Brazil. Initially, it addresses and delimits the concept of institutional dialogue to demonstrate the possibility of a dialogical relationship between politics and law in the construction of the decision-making process and constitutional interpretation. In the following, he investigates his experience both in the Canadian institutional arrangement and in the recent and new positions of the Constitutional Court of South Africa. Finally, concludes that institutional dialogues are facilitators instruments for overcoming blocks because they can create a qualified dialogue between State powers and also with segments of society, putting cracks in separation of powers often generated by model centralized in the judge to decide cases about public policies.

KEYwords: Institutional Dialogues - Separation of Powers - Dialogical Relation - Institutional Arrangements.

\section{INTRODUÇÃO}

Em tempos de crise de representação política² e também governamental ${ }^{3}$, uma das vias de solução vislumbrada é a substituição do presidencialismo por outro sistema de governo, notadamente o semipresidencialismo ou o parlamentarismo ${ }^{4}$. Atualmente tramitam,

2 Para se investigar acerca da crise da democracia representativa no Brasil, por todos, CAVAZANNI, 2014.

3 Sobre a crise governamental no Brasil e propostas para o seu enfrentamento ver: GUNDIM, 2018.

4 Embora experimentado por expressivo período durante o Império e com curta duração durante o governo de João Goulart, o parlamentarismo foi rejeitado pela população 
no Senado Federal brasileiro, três propostas de emenda constitucional que objetivam inserir, no país, o sistema parlamentarista de governo ${ }^{5}$.

Há no Brasil - assim como em outros países latino-americanos - a figura do "hiperpresidencialismo", traço marcante em que se vislumbra a preponderância do Poder Executivo sobre os demais poderes, notadamente o Legislativo, o que acabaria por desconfigurar o equilíbrio que caracteriza a separação de poderes, razão pela qual é necessário o redesenho ou até mesmo a substituição do sistema de governo presidencialista pelo semipresidencialista ou parlamentarista.

$\mathrm{Na}$ mesma linha de problemas está a ampliação da atuação do Poder Judiciário e também do Supremo Tribunal Federal, alcançando questões de alta repercussão política ou social (algumas que poderiam ter sido resolvidas pelo Poder Legislativo e pelo Poder Executivo), além de críticas de ativismo judicial e de excessiva judicialização da política ${ }^{7}$ o que também enfatiza a necessidade de reorganização da separação de poderes.

É certo que o princípio da separação de poderes assume função essencial no constitucionalismo contemporâneo, ideia consignada já

brasileira nos plebiscitos de 1963 e de 1993, sempre em favor do presidencialismo. Sobre o assunto, FRANCISCO, 2018.

5 Em síntese, os projetos de emenda constitucionais são: (i) PEC n. ${ }^{\circ} 32$, de 2015, de lavra do senador Fernando Collor de Melo; (ii) PEC n. ${ }^{\circ}$ 102, de 2015, de autoria do senador Antonio Carlos Valadares; e (iii) PEC n. ${ }^{\circ}$ 9, de 2016, apresentadas por diversos parlamentares, mas que possui como primeiro signatário o senador Aloysio Nunes. A introdução do parlamentarismo por emenda constitucional desafia a manifestação popular direta do plebiscito de 1993 (que pode ser tida como expressão do poder constituinte originário), razão pela qual, sem outra consulta popular, tal medida é de duvidosa constitucionalidade (sobre o tema, FRANCISCO, 2018, bem como SANTOS, 2016.

6 Referida expressão é cunhada por Gargarella, ao ressaltar o desequilíbrio institucional dos países latino-americanos em função desse fenômeno (GARGARELLA, 2013). Antonio Hernández, por sua vez, assim trata sobre o hiperpresidencialismo: "Para nosotros este fenómeno se caracteriza por la concentración del poder en el presidente, mas allá de las competências fijadas por la Constitución, en desmedro de la división y equilibrio de los poderes $y$ de los principios de la democracia constitucional [...]” (HERNÁNDEZ, 2010, p. 186).

7 A diferença entre os termos e suas respectivas elucidações são feitas por Luís Roberto Barroso em: BARROSO, 2012. 
no artigo 16 da Declaração dos Direitos do Homem e do Cidadão de 1789, que o prevê como elemento essencial ao reconhecimento de um sistema constitucional dos Estados ${ }^{8}$. Na idade moderna, a separação de poderes é fórmula que viabiliza controles políticos de reciprocidade, vale dizer, uma verdadeira garantia contra abusos de poder mediante sistema de freios e contrapesos. ${ }^{9}$

Sob a premissa da importância do princípio da separação de poderes para a ordem democrática, surgem os seguintes questionamentos: de que forma atenuar as crises institucionais/governamentais, resguardar a separação de poderes, maximizar o grau de responsiveness ${ }^{10}$ e atingir de forma satisfatória os interesses maiores da sociedade?

8 O art. 16 da Declaração dos direitos do homem e do cidadão, marco da Revolução Francesa de 1789, diz: "Qualquer sociedade em que não esteja assegurada a garantia dos direitos, nem estabelecida a separação dos poderes não tem Constituição”.

9 Vale o esclarecimento de Wagner Gundim ao tratar a respeito do pensamento de Montesquieu sobre o princípio da separação de poderes como fórmula política: "É importante ressaltar aqui que a teoria da separação de poderes trabalhada por Montesquieu é extremamente inovadora e em nada se confunde com a divisão do governo em três espécies, como se procedia com os romanos, tampouco com aquelas proclamadas por Aristóteles (em sua obra A política), Maquiavel (em seu livro O príncipe) ou Locke (em sua obra Segundo tratado sobre direito civil). Enquanto para Aristóteles, Maquiavel e Locke a ideia tripartite de consubstancia em mera divisão de poderes, é apenas em Montesquieu que a tripartição de poderes se apresenta como espécie de limitação do poder político, vale dizer, funciona como fórmula de controles políticos recíprocos, atuando como verdadeiro sistema de freios e contrapesos" (GUNDIM, 2018).

10 "Por responsiveness entende-se uma específica qualidade do instituto da representação política e, por conseguinte, da democracia representativa. Trata-se de um atributo concernente ao grau de aproximação entre a vontade do eleitor e as políticas adotadas pelos governantes. Quanto maior o grau de responsiveness na representação política, maior será a vinculação entre os interesses dos representados e a atuação dos representantes; em um grau absoluto de responsiveness, haveria o patamar de um mandato imperativo, em que a atuação do representante político é plenamente vinculada pela vontade dos representados. Em contrapartida quanto menor o grau de responsiveness, mais acentuada será a independência dos representantes em relação aos representados; em um grau absoluto de ausência de responsiveness, haveria o grau máximo da denominada crise de representatividade, quando não há qualquer vinculação entre eleitos e eleitores “(LORENCINI; GUNDIM, 2017, p. 377-378). 
A proposta apresentada neste estudo é o fortalecimento de "diálogos institucionais" pelos quais é possível o reencontro da teoria da separação de poderes pela efetiva conjugação de independência e de harmonia entre as instituições públicas, preconizando não uma hegemonia, preponderância ou individualismo de cada uma das esferas de poder. $\mathrm{O}$ diálogo institucional emerge como conexão contingencial no processo de construção político-decisional e na interpretação constitucional, com o fito de maximizar não apenas a participação popular, mas também a concreção dos maiores interesses da sociedade.

Para alcançar seu objetivo geral e seu objetivo específico, este estudo é divido em 3 tópicos. No primeiro, apresentará o conceito e as características básicas do que se entende por "diálogos institucionais", trazendo aporte teórico que servirá de base para responder à problemática que ora se propõe. Nos itens 2 e 3, faz-se uma verificação da teoria no campo da práxis, para então, sob um enfoque calcado na experiência do Canadá e da África do Sul, reforçar as hipóteses de pesquisa que apoiarão o estudo no seu desenvolvimento. ${ }^{11}$ Em tópico conclusivo, sugerirá o aprofundamento do diálogo institucional no Brasil como mecanismo de aprimoramento da fórmula democrática, tanto para a construção das decisões políticas e judiciais, como na interpretação constitucional.

A metodologia empreendida no estudo é essencialmente de caráter dialético, haja vista que buscará, por meio da análise de teses e de antíteses, apresentar síntese com relação aos argumentos propostos, permitindo a criação de uma nova tese: a adoção dos "diálogos institucionais" no Brasil como aprimoramento da fórmula democrática.

11 A pesquisa da experiência do Canadá se justifica porque é um país federativo, com ordem constitucional de 1982 e também por apresentar importante área de interseção entre Civil Law e Common Law (o que o sistema normativo brasileiro tem marcadamente procurado especialmente com as reformas da Emenda Constitucional 45/2004). Já a África do Sul também é um país de constitucionalismo jovem, cercado de desigualdades e déficits sociais e, tal como o Brasil, tem construído seu sistema jurídico com a participação importante de sua Corte Constitucional. 
Há, também, o emprego do método dedutivo e indutivo, a partir da interpretação dos sistemas constitucionais e de decisão da experiência dos países analisados como parâmetros.

Enfim, o propósito é contribuir para o desenvolvimento do conhecimento, aprofundando o estudo dos "diálogos institucionais" e na perspectiva brasileira.

\section{DIÁLOGOS INSTITUCIONAIS}

Há várias concepções sobre diálogos institucionais, com alcances e propósitos descritivos distintos e fundamentos normativos diversos ${ }^{12}$. Entretanto, em todas elas entende-se por diálogos institucionais o equilíbrio de forças e de participação entre os sujeitos componentes, oportunidade em que se estabelecem mecanismos dialógicos coordenados no sentido de que nenhum dos poderes tenha efetivamente a "última palavra", mas sim a "última palavra provisória" (ANDRÉA, 2018, p. 138). Segundo Danilo Nunes Cronemberger Miranda, "importa ter em mente que teorias do diálogo partilham a crença de que decisões são inevitavelmente provisionais. Existe vida política e constitucional após a sentença do Tribunal Constitucional” (2015, p. 65).

A compreensão do significado de "diálogo" vai além da simples postura pessoal aberta a "conversa". Para não se resumir a ações voluntaristas e incertas, a postura dialógica possui técnicas e métodos capazes de proporcionar níveis qualitativos de interlocução entre os participantes e, por consequência, abre um universo de possibilidades de compreensão e convergências entre personagens com pensamentos

12 O propósito deste estudo não é descrever minuciosamente técnicas de diálogo institucional ou no que se diferenciam de conversas ou de tradicionais tentativas de conciliação, mas apontar para a necessidade mudança de técnica de trabalho na atuação jurisdicional com a finalidade de fortalecimento democrático. Para abordagens mais aprofundadas, BATEUP, 2006. 
e interesses que inicialmente não estavam alinhados, notadamente representantes de poderes estatais e de segmentos da sociedade. ${ }^{13}$

Os participantes do procedimento deliberativo procuram influenciar a decisão que será tomada pelo governo, mas após a decisão, a discussão permanece aberta à possibilidade de diálogo contínuo, de tal modo que a decisão é sempre provisória, seja porque os mecanismos de decisão e a própria decisão são imperfeitas, seja nem sempre as decisões são consensuais e os discordantes podem aceitar uma decisão inicial se tiverem oportunidade de alterá-la no futuro (ANDRÉA, 2018, p. 138).

A expressão "diálogos institucionais" é gênero que comporta duas espécies: diálogos interinstitucionais e diálogos intrainstitucionais. O primeiro designa a relação entre diferentes poderes de Estado, enquanto o segundo aponta para as relações dialógicas entabuladas dentro de um mesmo poder estatal (ANDrÉA, 2018, p. 138).

Cláudia de Oliveira Fonseca afirma que "a expressão 'diálogo institucional' tem sido utilizada para descrever a possibilidade de interação entre os tribunais e os poderes políticos no que diz respeito à interpretação de direitos constitucionais" (FonseCA, 2014, p. 76). Trata-se de conceito voltado, com destaque, para a relação entre Poder Judiciário e Poder Legislativo, na qual existiriam as tensões quanto a quem seria o detentor da "última palavra" na interpretação do ordenamento jurídico. Destaca José dos Santos Carvalho Filho (2014, p. 173):

[...] um Estado de Direito não pode pautar-se pela preponderância de uma função estatal em relação às demais. É preciso que se busque o equilíbrio institucional, em que haja responsabilização conjunta e diálogo entre juiz e legislador para a proteção dos direitos fundamentais.

Essa harmonização, que permite o exercício da atividade jurisdicional contramajoritária paralelamente à manifestação do Legislativo, consubstancia o que se convencionou chamar de

13 Sobre métodos de diálogo, LEDERACH, 2010, e SCHAFER; KARLINS, 2015. p. 193. 
modelo de diálogo, caracterizado pelos permanentes diálogos institucionais entre Judiciário e Parlamento.

O judicial review é parte do diálogo entre juízes e legisladores, promovendo decisões democráticas. ${ }^{14}$ Viabilizando diálogo interinstituticional, uma decisão do Poder Judiciário pode ser revista pelo Poder Legislativo com edição de nova lei ordinária ou emenda constitucional, quando então o Poder Judiciário pode conferir deferência à posição do Poder Legislativo ou, uma vez provocado, novamente declarar a inconstitucionalidade da lei ou emenda; na ordem, o Poder Legislativo pode permanecer silente quanto à decisão judicial polêmica, o que pode configurar modalidade de resposta, embora com eventuais custos políticos perante os eleitores representados ${ }^{15}$.

Do mesmo modo, o diálogo institucional também deve ser aplicável às relações interinstitucionais do Poder Judiciário e Poder Executivo, como por exemplo no que se refere à concretização de políticas públi$\mathrm{cas}^{16}$, tendo como típico exemplo o caso Grootboom ${ }^{17}$ da África do Sul.

14 Segundo Carlos Alexandre de Azevedo Campos: "O grande vilão não é o controle em si, nem mesmo, de um modo geral, o ativismo judicial que pode vir a ser legítimo nas hipóteses de insistente omissão ou impasse político-legislativo, e sim a ideia de supremacia judicial, de tribunais como senhores absolutos das constituições. Esta é a perspectiva apriorística e irremediavelmente inconsistente com um governo democrático” (2015a, p. 198).

15 "No modelo tradicional, o Legislativo, caso esteja inerte por preferência política em manter-se omisso, sempre terá, diante de uma decisão judicial que contrarie interesses da sociedade a possibilidade de invocar, em seu favor, a supremacia do Judiciário. Já no modelo dialógico, ao não reagir à decisão judicial constitui-se uma resposta: o Legislativo preferiu abdicar de sua possibilidade de reação. Esta resposta explicita a abstenção a seus representados, que terão oportunidade de, em momento próprio, desaprovar essa inapetência legislativa." (SILVA; MOURA; BERMAN; VIEIRA; TAVARES; VALLE, 2012, p. 109).

16 De acordo com Maria Paula Dallari Bucci, no que se refere ao controle judicial de políticas públicas: “O caminho que se vislumbra, portanto, é a 'processualização' das iniciativas objeto dos processos judiciais, isto é, a criação de mecanismos formais ou informais de mediação, por meio de 'diálogos institucionais' que permitem o estabelecimento das etapas e meios necessários para a implementação dos direitos e das políticas públicas” (2013, p. 199).

17 A Corte Constitucional sul-africana tem sido parâmetro importante na concretização de direitos sociais. Por exemplo o caso Grootboom envolveu a Sra. Grootboom, que 
Contudo, mesmo atuando de modo dialógico, decisões judiciais não ficam imunes ao efeito backlash. Como efeito colateral de decisões judiciais em temas que dividem a opinião pública, até mesmo conclusões de vanguarda na defesa dos direitos fundamentais podem provocar reações contrárias com forte apelo emocional, repercutindo na opinião pública e em escolhas eleitorais conservadoras, resultando, ao final, em leis potencialmente capazes de criar situação normativa ainda pior do que a que havia antes das decisões judiciais questionadas. ${ }^{18}$ A questão central das teorias dialógicas é a relação entre política e direito, é a articulação no processo interativo dos atores políticos envolvidos antes e depois da construção das decisões judiciais (ANDRÉA, p. 140). É perfeitamente possível a possibilidade de interação e contribuição entre poderes ao longo do processo de construção da decisão, o que pode antecipar os benefícios com a integração, desde logo, das diversas visões ao longo da construção da decisão ${ }^{19}$.

A teoria dos diálogos institucionais encontra respaldo, também, na formulação de Peter Häberle de que é necessária uma abertura da

havia perdido o seu residência humilde que habitava"b com sua irmã e três filhos na Cidade do Caboe, muito embora o Estado já tivesse desenvolvido um programa amplo para permitir que os moradores nessas precárias condições tivessem uma vida adequada, a Corte Constitucional foi além e declarou que o governo criasse programa análogo voltados às pessoas que não possuíam qualquer tipo de moradia em razão de despejos, incêndios ou enchentes, determinando, por consequência, a apresentação de um programa político de moradia em caráter emergencial aos setores mais necessitados da sociedade. Sobre o assunto, NETO, 2014.

18 Sobre o tema, KLARMAN, 2011. Embora Michael Klarman descreva casos de julgamentos progressistas em sua exposição, a reação política adversa não é necessariamente conservadora mas contrária à linha de entendimento firmada pelo Poder Judiciário, de modo que o backlash pode ser dar por diferentes orientações ideológicas.

19 A esse respeito, SILVA; MOURA; BERMAN; VIEIRA; TAVARES; VALLE, 2012, p. 101. Conforme ANDRÉA (2018), os casos de declaração do "Estado de Coisas Inconstitucional" pela Corte Constitucional da Colômbia marcam decisões flexíveis, construídas em conjunto com os demais poderes, sob sua coordenação, alternativas para a superação da situação de inconstitucionalidade, por meio de acompanhamento e dilação de sua jurisdição no tempo (caso emblemático é o do deslocamento forçado de pessoas - sentencia T-025 de 2004). 
interpretação da Constituição, compreendendo-se como um produto de contribuição de diferentes atores e perspectivas teóricas, o que conduz a uma sociedade aberta de intérpretes da Constituição. Ainda, conforme salientado pelo mencionado autor: "no processo de interpretação constitucional estão potencialmente vinculados todos os órgãos estatais, potências públicas, todos os cidadãos e grupos, não sendo possível estabelecer-se um elenco cerrado com numerus clausus de intérpretes da Constituição” (HäBERLE, 1997, p. 13).

Promovendo o equilíbrio institucional, os modelos de diálogos se pautam pela acomodação de interpretações do ordenamento jurídico e pela reengenharia de posturas institucionais que causem distorções no sistema e desarmonia entre os poderes (Augusto; Andréa, 2016, p. 202-203). Diálogos institucionais podem derivar tanto de desenhos institucionais (pela Constituição e por demais atos normativos) ${ }^{20}$ como de uma postura voluntária e própria da Corte Judicial. ${ }^{21}$

Assim, com diálogos institucionais (inter ou intra) emergem como via útil no constitucionalismo contemporâneo, de modo que a questão deixa de ser quem deve interpretar ou que poder deve fazê-lo com primazia e, voltando as atenções para "uma proposta cooperativa pela qual as instituições possam compartilhar fundamentos comuns ao operacionalizar as ordens jurídica e política da realidade democrática” (ARAúJo, 2014, p. 31).

Portanto, as decisões tomadas teriam caráter parcialmente definitivo com o objetivo de aperfeiçoar sistema cooperativo e progressivo, valendo-se das relações entre instituições, numa comunidade dialógica e convergente (Augusto; Andréa, 2016, p. 203). José dos Santos Carvalho Filho (2014, p. 176) pontua que:

É possível perceber um acréscimo no coeficiente democrático da deliberação sobre direitos ou políticas públicas no contexto

20 O Canadá é um bom exemplo em que o desenho institucional foi construído propositalmente para favorecer o diálogo institucional.

21 A África do Sul é um exemplo em que a própria Corte estabelece o diálogo institucional, independentemente de qualquer previsão legal. 
do modelo dialógico, uma vez que a participação dos indivíduos no processo, direta ou indiretamente - por meio dos seus representantes eleitos -, legitima a decisão. Assim, em sistemas em que o controle judicial de constitucionalidade conviva com a participação do Poder Legislativo no debate constitucional, a pluralidade tende a enriquecê-lo e, portanto, a torná-lo mais amplo, democrático.

Destarte, trata-se da transformação ou migração do monólogo judicial (embora embasado na visão tradicional do contraditório e da ampla defesa) para um amplo e equilibrado diálogo institucional, capaz de enriquecer o conhecimento do problema judicializado e reduzir a tensão entre a proteção judicial dos direitos fundamentais e a tomada de decisão democrática. Todas as instituições tomam posições ativas e abertamente responsáveis pela construção do significado material da Constituição, atuando no diálogo que "questiona a possibilidade de predomínio de qualquer dos Poderes constituídos, bem como a tradicional teoria da separação dos poderes, como parâmetros únicos à formulação de um Estado Democrático” (Araújo, 2014, p. 33).

Enfim, diálogos institucionais propõem um novo olhar sobre a separação de poderes no contexto de temas judicializados, e o modo como as instituições podem e devem se comportar, além de oferecer um novo parâmetro para medir a interação entre instituições, pautado na capacidade delas efetivamente participarem e promoverem o diálogo entre si (Miranda, 2015, p. 66). As decisões judiciais passam a ser consequências de diálogo colocado na área de sobreposição da arena pública e da arena jurídica. No que se refere a leis antigas, uma nova rodada de debates apresenta-se para restaurar a legitimação em torno de lei eventualmente declarada inconstitucional (CLÈve; LorenzetTo, 2015, p. 402-403).

André Reis Lacerda, valendo-se das lições de Jorge Munhós de Souza (2013, p. 5082), destaca um núcleo comum de características que poderia agrupar todas as diversas teorias de modelos dialógicos, no seguinte sentido: 
i) recusa a visão juriscêntrica e do monopólio judicial na interpretação da constituição, a qual deve ser exercida legitimamente também por outros poderes; ii) rejeição à existência de uma última palavra, ou, pelo menos, de que a corte detenha por meio da revisão judicial - nos casos abstratos; iii) provê mecanismos institucionais para que as pessoas e instituições respondam às decisões dos tribunais com as quais não concordam por outros meios que não apenas a emenda constitucional ou recomposição da corte; iv) prevêm (SIC) alguma forma de controle político da possível violação de direitos (não se confundindo com a revisão judicial); v) autoriza o controle de constitucionalidade, com a opção do desacordo político; vi) nutre expectativa de que por meio de alguns incentivos institucionais os parlamentos possam levar a sério os direitos.

Em razão da inafastabilidade da prestação jurisdicional apresentada como garantia fundamental no art. $5^{\circ}$, XXXV, da Constituição, em não havendo meios para construir diálogo institucional (p. ex., por resistência injustificada dos interlocutores dos demais poderes estatais), caberá ao órgão judicial competente proferir a decisão apropriada segundo seu entendimento (ou seja, no modelo tradicional). Contudo, viabilizando-se o diálogo institucional, haverá agregação de conhecimentos de diferentes fontes, a dificuldade contramajoritária é potencialmente atenuada, aproximando os poderes estatais e o próprio povo como partícipes na construção do significado constitucional.

Para além disso, o diálogo seria uma garantia de que os ramos do Poder que necessitam prestar contas de suas atividades periodicamente aos seus eleitores, posicionem-se e respondam às decisões judiciais com as quais não concordem, gerando maior transparência e accountability ${ }^{22}$. Como bem destacam Clémerson Merlin Clève e Bruno Meneses Lorenzetto (2015, p. 409):

22 Em apertada síntese, nos dizeres de Bruno César Lorencini e Wagner Wilson Deiró Gundim "accountabilitty perfaz os planos dos deveres de informação e justificação acerca de 
[...] faz parte do amadurecimento das democracias a tradução de desacordos profundos e irreconciliáveis em espaços adequados de deliberação, como meio de resguardar a própria democracia. Não se espera com isso, que os diálogos conduzam necessariamente a um consenso ou que a parte que possui melhores razões venha efetivamente a prevalecer. Há, afinal, uma série de fatores passionais que podem levar a formação de consensos e a tomada de decisões casuísticas para além dos bastiões da racionalidade. Aquilo que se combate são os 'monólogos majoritários', pois, em uma democracia, os desacordos irão surgir, mas, as instituições que permitem que as pessoas continuem a discordar devem permanecer.

Neste passo, o Poder Judiciário pode continuar a ser o lócus final de um conflito, como corolário da segurança jurídica, motor de pautas progressistas e também para agente de mobilização que combate um status quo injustificável. Entretanto, não será ele, necessariamente, o astro ou o detentor exclusivo da última palavra (salvo em casos de interlocução inviável), porque diálogos institucionais fomentadores da "última palavra provisória" e de "rodadas procedimentais", potencialmente permitem sequências enxergando com novas lentes a revisão judicial (ANDrÉA, 2018, p. 143).

Em países com controle judicial forte, como Brasil, Estados Unidos e Alemanha, existe dificuldade maior de se estabelecer um diálogo institucionalizado, mas, mesmo assim, ele ainda se apresenta como viável e altamente recomendável no caso brasileiro (em razão do elevado nível de judicialização de políticas públicas). Países como Nova Zelândia, Canadá e Reino Unido, nos quais há controle judicial "fraco", a figura do diálogo já é vista com maior naturalidade (Tushnet, 2008).

A seguir serão apresentadas duas experiências de diálogos institucionais marcantes. A canadense é considerada a principal e mais antiga,

todas as condutas governamentais (2017). Para maior aprofundamento da temática da responsabilidade política e suas facetas, recomenda-se a leitura de LORENCINI, 2015. 
além de se destacar pelo seu desenho institucional (especialmente sua Constituição) totalmente inclinado ao diálogo. A sul-africana é mais recente e os diálogos se realizam não em virtude de um arranjo institucional, mas sim em decorrência do posicionamento criativo e protagonista da Corte Constitucional.

\section{DIÁLOGO INSTITUCIONAL NA EXPERIÊNCIA DO CANADÁ}

Em primeiro lugar cabe destacar que o Canadá é uma sociedade multiética componente do Reino Unido, e possui tradição da Commonwealth com aspectos próprios de Civil Law (pela colonização mista inglesa e francesa). ${ }^{23}$ Entretanto, devido ao esgotamento institucional para efetivação de direitos fundamentais, em especial de grupos indígenas, a partir da segunda metade do século XX firma-se jurisdição constitucional que busca garantir os direitos às minorias também zelar pela manutenção do espaço próprio do Parlamento.

Com sua Constituição de 1982, o Canadá apresenta tríplice significado político-institucional com relevantes efeitos na área jurídica: proteção de direitos; ruptura com o positivismo de matriz anglo-saxônica; e redesenho da separação de poderes, garantindo o equilíbrio entre competências parlamentares e proteção judicial do núcleo de direitos fundamentais (Silva; Moura; Berman; Vieira; Tavares; Valle, 2012, p. 61).

Cientes dos efeitos perniciosos de supremacia judicial associada ao controle de constitucionalidade (tal como se dá pelo paradigma norte-americano), os canadenses elaboraram sua Carta de Direitos de

${ }^{23}$ Devido a sua extensão territorial e frio extremo de algumas regiões, o Canadá incorporou a necessidade de incentivo à colonização de suas terras, comportando atualmente uma das maiores comunidades estrangeiras do mundo, com políticas de inclusão e respeito às diferenças étnicas, o que influência seu próprio desenho institucional e facilita o cooperativismo. 
1982 com um sistema dinâmico de separação de poderes, impedindo que o Poder Judiciário tivesse a "última palavra” sobre a interpretação constitucional. Assim, pautaram-se por um controle de constitucionalidade "fraco" e permitiram a alteração da Carta de Direitos por emenda constitucional com requisitos qualificados, com a possibilidade do Judiciário invalidar leis que não se coadunassem com o preceito constitucional, mas, ao mesmo tempo, armando o Parlamento com competências para impor limites justificados aos direitos ou superá-los por períodos de tempo limitado.

A carta canadense inovou em duas cláusulas que identificam o cerne do sistema: as seções 1 e 33. Pela Seção 1, cuidando de "cláusula geral de limitação de direitos", o Legislador pode restringi-los apenas em medidas razoáveis e devidamente justificadas. Com isso é possível afastar práticas indesejadas de "ativismo judicial" porque a exigência de reserva de lei para impor limitações a direitos força o Parlamento e o Governo a promoverem debate na comunidade para demonstrar a "necessidade de medida limitativa", favorecendo o diálogo institucional e o comprometimento da harmonia entre os poderes (SILVA; Moura; Berman; Vieira; Tavares; Valle, 2012, p. 62).

Já a Seção 33 da Carta de 1982 cuida do overriding ${ }^{24}$, segundo o qual o Parlamento pode editar texto legislativo que configure e limite direito consagrado pela Carta nas Seções 2 e de 7 a 15, mesmo que já tenha sido objeto de juízo de reprovação pela Corte Constitucional. Com isso o Parlamento tem a prerrogativa de repudiar decisão judicial de censura a sua atuação, impondo, no entanto o ônus de assim dizer. Esse mecanismo completa-se com cláusula de limitação temporal: a

24 Similar ao overriding canadense, o parágrafo único do art. 96 da Carta Constitucional Brasileira de 1937, no contexto da concentração de competências na Presidência da República durante o Estado Novo, previu: "No caso de ser declarada a inconstitucionalidade de uma lei que, a juízo do Presidente da República, seja necessária ao bem-estar do povo, à promoção ou defesa de interesse nacional de alta monta, poderá o Presidente da República submetê-la novamente ao exame do Parlamento: se este a confirmar por dois terços de votos, em cada uma das câmaras, ficará sem efeito a decisão do Tribunal". 
lei elaborada pelo overriding (ou seja, aquela que já foi considerada incompatível com a Carta pelo Judiciário) nasce sob o signo de validade de cinco anos, após os quais, caso pretenda o legislativo que a norma ainda prevaleça, deverá novamente empreender sua aprovação, por meio da cláusula do notwithstanding ("não obstante") (Silva; Moura; Berman; Vieira; Tavares; Valle, 2012, p. 62-63). André Reis Lacerda anota (2013, p. 5085):

Segundo relatos dos canadenses, a experiência tem demonstrado que somente de forma extremamente excepcional essa cláusula é invocada - sobretudo pelo risco de previsíveis desgastes políticos. Os tribunais, nesta senda, já que não detêm a 'palavra final' sobre as questões constitucionais, se comprometem com uma análise mais cuidadosa e justificada antes de invalidar qualquer lei advinda do processo majoritário. E, de consequência, o Parlamento somente ultrapassaria as invalidações excepcionais quando categoricamente necessária para manutenção dos compromissos propostos na Carta de Direitos.

Além desses mecanismos, outros dispositivos e prerrogativas também materializam ou convidam ao diálogo institucional. Uma delas é a discricionariedade reconhecida ao Judiciário pela Seção 24 (1), para eleger remédio jurisdicional específico a determinada hipótese; e de outro lado a possibilidade do Judiciário desenvolver (valendo-se da discricionariedade de calibragem do remédio) provimentos jurisdicionais que provocam a interação com o Legislativo, já que submetidos a sua apreciação. São eles: a supervisory jurisdiction e os remedial issues.

Pela supervisory jurisdiction, o Judiciário pode proferir decisão judicial na composição de conflito inerente à efetividade da Carta de Direito, cujo cumprimento deva ser supervisionado pelo mesmo órgão jurisdicional, oportunidade em que o diálogo interinstitucional manifesta-se na resposta oferecida pelo Poder Executivo à determinação judicial e no acompanhamento, pelo Poder Judiciário, das dificuldades próprias da transposição para a prática das determinações construídas com o objetivo de tutelar direitos. 
Com os remedial issues, há a modulação de efeitos da decisão judicial, com o detalhamento sobre qual deve ser a atuação exigível do Legislativo (cuja colaboração se pressupõe em homenagem ao equilíbrio e harmonia entre os poderes estatais) (Silva; Moura; Berman; Vieira; Tavares; Valle, 2012, p. 63-64).

Em 1997, Allison Bushell e Peter Hogg analisaram casos decididos pela corte constitucional nos quais houve invalidação de normas, e verificaram 65 casos para concluir que houve diálogo entre a Corte e o corpo legislativo quando a decisão judicial foi aberta à reversão, modificação ou repúdio por parte do Legislativo. Segundo dados da pesquisa, em $80 \%$ dos casos examinados, à decisão judicial seguiu-se uma reação legislativa, incluindo aí também a anuência para com os termos da decisão judicial, caracterizando diálogo institucional (Bushell; Hogg, 1997).

Segundo Allison Bushell e Peter Hogg, a mesma decisão judicial (objeto de diálogo institucional), ostenta o condão de incluir na agenda deliberativa determinada matéria até então secundarizada nos trabalhos legislativos (seja por opção política, seja por percepção equivocada), além do que o diálogo institucional ainda teve o mérito de neutralizar os riscos associados à revisão judicial, notadamente a supremacia judicial (Silva; Moura; Berman; Vieira; Tavares; Valle, 2012, p. 65-66).

Os estudos de Allison Bushell e Peter Hogg foram criticados (Silva; Moura; Berman; Vieira; Tavares; Valle, 2012, p. 67-68), abrindo discussão sobre ter havido "diálogo com verdadeira deliberação" entre os poderes e ou mera "conversa". Essas críticas foram objeto de resposta por parte de Allison Bushell e Peter Hogg em 2007 (Bushell; Hogg; Wright, 2007), oportunidade em que, além de reafirmarem a resposta legislativa após o judicial review, na qual apontam que a última palavra poder ser (e quase sempre é) a do Legislativo, perdendo relevância a objeção da dificuldade contramajoritária da jurisdição constitucional, também destacaram que os críticos deveriam considerar mais o significado do fenômeno do que enfatizar 
a imputação de que o diálogo seria uma simples metáfora (Silva; Moura; Berman; Vieira; Tavares; Valle, 2012, p. 67-68).

\section{DIÁLOGO INSTITUCIONAL NA EXPERIÊNCIA DA ÁFRICA DO SUL}

Com história recente marcada pelo apartheid (autocracia racial e segregacionista entre brancos e negros que teve início em 1910 e durou boa parte do século XX), a África do Sul realizou transição negociada, com progressiva implementação da democracia e do respeito a direitos fundamentais desde meados da década de 1990 (PaumgartTEN, 2012, p. 151).

A Corte Constitucional da África do Sul exerce papel importante no constitucionalismo transformativo que emergiu no país na última década do século XX que, segundo Karl E. Klare, é "uma empreitada de mudança social de larga-escala por meio de processos políticos não violentos fundados no direito". ${ }^{25}$ Neste sentido, a Corte Constitucional tem superado métodos jurisprudenciais conservadores encrustados na cultura jurídica sul-africana, despontando por meio de interpretações criativas e garantindo a efetivação progressiva das normas fundamentais da Constituição de 1996, com ênfase na realização dos propósitos transformativos de Justiça Social (CAmpos, 2015b, p. 411).

A própria formação da Constituição de 1996 teve uma participação relevante da Corte Constitucional, pois o processo constituinte foi realizado em dois estágios distintos de negociação. Num primeiro momento, os partidos políticos instituíram a Constituição Provisória

25 Para Karl E. Klare, o constitucionalismo transformativo é um "projeto de promulgação, interpretação e execução constitucional de longo-prazo comprometido (não isoladamente, claro, mas em um contexto histórico de desenvolvimentos políticos propícios) em transformar as instituições políticas e sociais de um país e as relações de poder em uma direção democrática, participativa e igualitária” (KLARE, 1998, p. 151). 
em 1994, na qual estabeleceram 34 princípios fundamentais ${ }^{26}$ a fim de nortear um consenso sobre a Constituição definitiva. Num segundo momento, após longo processo de negociação, promulgou-se a Constituição definitiva de 1996, mas esse texto, antes de ter plena eficácia, foi certificado pela Corte Constitucional em relação aos princípios básicos da Constituição Provisória, vale dizer, o diploma constitucional foi submetido a teste de validade material pela Corte Constitucional (CAmpos, 2015b, p. 411).

Fato é que, desde o diploma provisório, a Corte Constitucional assumiu seu papel natural de guardiã da ordem constitucional e dos direitos humanos na África do Sul pós-Apartheid, tal como se deu, p. ex., no caso $S v$. Makwanyane and Another de 1995, oportunidade em que, numa clara resposta e repulsa ao regime de Apartheid que se valia da pena de morte contra pobres e negros, essa Corte definiu que, diante do silêncio legislativo e constitucional, seria de sua inteira atribuição julgar a controvérsia e decidiu, de forma unânime, valendo-se do princípio da dignidade da pessoa humana, que não seria admissível a pena de morte como parte do sistema normativo democrático (CAmpos, 2015b, p. 411).

Conforme destaca Carlos Alexandre de Azevedo Campos (2015b, p. 412):

26 Conforme PAUMGaRTTEN (2012, p. 161): “O Congresso Nacional Africano defendia que a Constituição deveria ser elaborada por uma assembleia constituinte eleita democraticamente, enquanto o Partido Nacional, temendo que o direito das minorias não fossem protegidos nesse processo, propôs que a Constituição fosse submetida a um referendo. As negociações começaram em 1991. Acordou-se que seria elaborada uma constituição de transição para que uma assembleia constituinte eleita elaborasse uma constituição definitiva. A Constituição Provisória continha 34 princípios constitucionais, os quais a nova constituição seria obrigada a cumprir. Incluíam-se entre esses princípios a democracia multipartidária, com eleições periódicas e sufrágio universal; a supremacia da Constituição sobre todas as outras leis; abolição ao racismo e ao sexismo; a proteção às liberdades e às igualdades; a separação dos poderes, com um sistema judiciário imparcial; a proteção da diversidade linguística e cultural; a criação de um tribunal constitucional. Por isso, a necessidade de certificação pelo Tribunal Constitucional: para verificar se o texto substitutivo e permanente estava de acordo com os princípios estabelecidos no texto provisório". 
Ao lado de ser ativista, a Corte Constitucional sul-africana tem também procurado cumprir um papel equilibrado na afirmação de direitos em questões socialmente muito controvertidas e na alocação de recursos e benefícios públicos em torno dos direitos sócio-econômicos, buscando estabelecer diálogos com os outros poderes em torno da melhor forma de realizar as esperanças e pretensões transformativas da nova ordem constitucional e democrática. As sentenças aditivas de princípio têm sido uma ferramenta fundamental para esta postura judicial.

Diversamente do modelo canadense, no qual o diálogo institucional encontra-se no próprio desenho constitucional (especialmente por mecanismos institucionais de reversão ou modificação legislativa das decisões judiciais, override, notwithstanding clause, supervisory jurisdiction e os remedial issues), a Corte Constitucional sul-africana, embora sem previsão institucional acerca de diálogos, tem realizado interpretações criativas e empregado de técnicas de decisão (tais como as sentenças aditivas de princípios) ${ }^{27}$ pelas quais o Legislativo se vê levado a legislar, seja em situações de omissões inconstitucionais, seja para aprimorar a legislação com defeitos constitucionais.

A Corte Constitucional não se imiscui nas competências próprias do Poder Legislativo de antemão, embora determine a direção a ser tomada e estabeleça prazo razoável para o suprimento da falha ou omissão por parte do Legislador. Com isso, a Corte Constitucional proporciona diálogo institucional entre Poderes, preservando a legitimidade democrática da decisão judicial e ao mesmo tempo protege o texto constitucional, notadamente direitos fundamentais (CAmPos, 2015b, p. 412).

27 Cumpre destacar que as sentenças aditivas encontram seu berço e evolução teórica relevante na Itália. Especificamente as sentenças aditivas de princípio "reconhecem a omissão inconstitucional e indicam os princípios básicos que o legislador deverá adotar na elaboração da norma ausente para que assegure a criação de uma norma compatível com os ditames constitucionais [...] a adoção das decisões manipulativas aditivas de princípio sustenta a aplicação do texto constitucional por meio de um princípio para a supressão da omissão legislativa, evitando uma interferência judicial ao âmbito de tomada de decisão dos demais poderes políticos.” (MENEZES; SILVA, 2014). 
No campo das liberdades fundamentais e dos direitos da igualdade, a Corte Constitucional também procedeu de forma dialógica em decisão acerca do casamento entre homoafetivos no caso Lesbian and Gay Equality Project v. Minister of Home Affairs (2006). Julgando inconstitucional a legislação ordinária na parte em que negava às uniões homoafetivas os mesmos benefícios, responsabilidades e status do casamento entre heterossexuais, a Corte fundamentou sua decisão na violação à igualdade e à dignidade da pessoa humana, bem como na falta de observância e valor à diversidade e ao pluralismo na sociedade sul-africana.

A Corte Constitucional determinou a suspensão, por um ano, dos efeitos da decisão, conferindo prazo ao Parlamento para regulamentar os direitos assegurados pela sua decisão e, caso o Legislador permanecesse em silêncio, "justiça e equidade" exigiriam que a legislação ordinária passasse a ser interpretada a fim de garantir o casamento civil entre homoafetivos. Em típica sentença aditiva, a Corte Constitucional instaurou diálogo e conferiu ao Parlamento a última palavra sobre o tema, resultando em mudança normativa efetiva (CAmpos, 2015b, p. 412-413).

Em matéria de direitos socioeconômicos, no caso Government of the Republic of South Africa and Others v. Grootboom and Others, (2000), Irene Grootboom e mais cerca de 900 pessoas (entre adultos e crianças) estavam vivendo em condições degradantes e buscaram na Justiça a efetivação do direito à moradia prevista na Constituição Sul Africana. A Corte Constitucional julgou em favor de Grootboom e outros $^{28}$, obrigando o poder público a criar e adotar, conforme "recursos

28 Confira-se trecho da decisão da Corte Constitucional (tradução livre): "Esse caso demonstra o desespero de centenas de milhares de pessoas que vivem em condições deploráveis pelo país afora. A Constituição obriga o Estado a agir positivamente para amenizar essas condições. A obrigação consiste em providenciar acesso à moradia, saúde, comida e água suficientes e previdência social para os necessitados e seus dependentes. O Estado também deve promover as condições que permitam que os cidadãos também obtenham acesso à terra de modo equitativo. Os que necessitam têm 
orçamentários disponíveis”, um programa abrangente e coordenado para, progressivamente, efetivar o direito à moradia adequada, com "medidas razoáveis". Foi reconhecido explicitamente a justiciabilidade dos direitos sociais (direito à moradia previsto na s. 26 da Constituição da África do Sul), de modo que a Corte Constitucional, mesmo sem ações concretas e imediatas, abriu diálogo sobre políticas públicas prioritárias com o Governo (Paumgartten, 2012, p. 156).

Conforme ressalta Carlos Alexandre de Azevedo Campos (2015b, 413):

Portanto, a prática da Corte Constitucional sul-africana ensina que uma corte poder ser ativista e ainda assim interagir com os outros poderes políticos sobre temas moral e politicamente relevantes e divisivos, ou que exijam escolhas alocativas de recursos - a Corte procura garantir os direitos fundamentais e sociais por meio de um equilíbrio entre endossar e redirecionar as políticas públicas transformativas do governo, entrando em diálogo com as outras instituições como forma de assegurar a melhor e mais legítima forma de realização dos valores constitucionais. Percebendo lacunas e omissões, em vez de corrigir imediatamente essas falhas, a Corte entra em diálogo com os poderes políticos, proferindo sentenças por meio das quais delimita principiologicamente como essas lacunas serão preenchidas segundo escolhas definitivas pelos órgãos legitimados pelo voto popular.

Nessa decisão a Corte Constitucional da África do Sul conciliou valores democráticos (que impõem políticas públicas por parte

o direito correspondente de exigir judicialmente o cumprimento dessas obrigações. É inquestionável que é uma tarefa extremamente difícil para o Estado cumprir essas obrigações na situação que prevalece em nosso país. Aliás, isso é reconhecido pela Constituição a qual expressamente dispõe que o Estado não é obrigado a gastar mais do que tem ou implementar esses direitos imediatamente, contudo, que apesar disso, trata-se de direitos, e a Constituição obriga o Estado a dar efetividade a eles. Essa é uma obrigação que o Tribunal pode, nas circunstâncias apropriadas exigir o cumprimento" (ÁFRICA DO SUL, 2000). 
do Legislativo e do Executivo) com a efetivação judicial dos direitos econômicos, culturais e sociais (DESCs) que exigem pronunciamento e proteção judicial, dialogando de maneira interinstitucional.

\section{CONCLUSÃO}

Os diálogos institucionais são instrumentos facilitadores para a superação de bloqueios porque podem criar interlocução qualificada entre os poderes estatais e também com segmentos da sociedade, recompondo fissuras na separação dos poderes muitas vezes gerada pelo modelo juriscêntrico de solução de judicializações de políticas públicas. Mais do que postura voluntarista aberta à "conversas interpessoais", os padrões e métodos de diálogo (intra e interinstitucional) podem reestruturar a responsiveness em países como o Brasil. As experiências do Canadá e da África do Sul demonstram que diálogos institucionais proporcionam ganho democrático e preservam as competências de cada um dos poderes. Enquanto no Canadá a experiência decorre diretamente do texto constitucional (pelo overriding e pela cláusula do notwithstanding), na África do Sul o diálogo institucional deriva de interpretações da Corte Constitucional em casos concretos, concretizando mandamentos constitucionais notadamente na proteção dos direitos fundamentais.

No Canadá, o controle de constitucionalidade "fraco" permite o afastamento da decisão da Suprema Corte pelo Legislativo e pelo Executivo, mediante mecanismo próprios (como forma de proteção de competência) e devolução da matéria aos poderes políticos, conformando o diálogo a premissas da ordem democrática e institucional.

$\mathrm{Na}$ África do Sul, o controle de constitucionalidade "forte" tem sido usado em sentenças pelas quais a Corte Constitucional insta a produção de atos normativos pelos poderes políticos. Ao determinar a concretização de programas, metas e deveres ao 
Legislativo e ao Executivo, a Corte Constitucional tem empregado mecanismos de diálogo institucional, legitimando sua atuação à luz do caráter democrático.

Em vista da intensa judicialização de políticas públicas vividas no Brasil, na qual não raras vezes os pronunciamentos judiciais escoram-se em padrões tradicionais de o magistrado ter o "monopólio da última palavra", há elementos úteis de conhecimento que podem ser colhidos nas experiências do Canadá e da África do Sul. Em nosso controle de constitucionalidade "forte", métodos de diálogos institucionais ainda são pouco aplicados no Brasil mas merecem melhor consideração em favor da legitimidade de pronunciamentos judiciais e do accountability.

\section{REFERÊNCIAS}

ÁFRICA DO SUL. Corte Constitucional de Justiça. CCT 11/00. Government of the Republic of South Africa and Others v. Grootboom and Others. Decisão de 4 out. 2000. Disponível em: http://www.constitucionalcourt.org.za. Acesso em: 17 ago. 2016.

ANDRÉA, Gianfranco Faggin Mastro. Estado de coisas inconstitucional no Brasil. Rio de Janeiro: Lumen Juris, 2018.

ARAÚJO, Luis Cláudio Martins de. Supremacia ou Diálogos Judiciais? O Desenvolvimento de uma Jurisdicção Constitucional Verdadeiramente Democrática a partir da Leitura Institucional. Revista do Instituto do Direito Brasileiro, Vol 3, no , p. 1-45. Lisboa: 2014, p. 31. Disponível em: https:// blook.pt/publications/publication/63825009035f. Acesso em: 12 abr. 2016. AUGUSTO, Marcela Vaz; ANDRÉA, Gianfranco Faggin Mastro. Ações coletivas como instrumento de concretização de políticas públicas: o caso do ativismo judicial dialógico no TJSP. Revista de Direito Constitucional e Internacional, vol. 97. ano 24. p. 179-209. São Paulo: Ed. RT, set.-out.2016. BARBOZA, Estefânia Maria de Queiroz; KOTINDA, Thierry Chozem Zamboni. Direitos fundamentais e controle judicial. Pensar, v. 19, n. 1, jan./abr.2014. 
BARROSO, Luís Roberto. Judicialização, Ativismo Judicial e Legitimidade Democrática. (Syn) thesis, Rio de Janeiro, vol. 5, n. ${ }^{\circ}$ 1, 2012.

BATEUP, Christine. The dialogic promise: assessing the normative potential of theories of constitucional dialogue. Brooklyn Law Review, v. 71, p. 1.109-1180, 2006.

BUCCI, Maria Paula Dallari. Fundamentos para uma teoria jurídica das políticas públicas. São Paulo: Saraiva, 2013.

BUSHELL, Allison A.; HOGG, Peter W. The Chapter dialogue between courts and legislatures (or perhaps teh Chapter of Rights isn't such a bad thing after). Osgoode Law Journal, v. 35, n. 1, p. 75-124, 1997.

BUSHELL THORNTON, Alisson; HOGG, Peter W.; WRIGHT, Wade K. Charter dialogue revisited: or "much ado about metaphors". Osgoode Law Journal, v. 45, n. 1, p. 1-65, 2007.

CAMPOS, Carlos Alexandre de Azevedo. Supremo Tribunal Federal, Política e Democracia. In SARMENTO, Daniel (coord.). Jurisdição Constitucional e Política. Rio de Janeiro: Forense, 2015a.

CAMPOS, Carlos Alexandre de Azevedo. As sentenças manipulativas aditivas - os casos das cortes constitucionais da Itália, da África do Sul e do STF. Revista de Processo, Vol. 246/2015, p. 403 - 427, Ago. 2015b.

CARVAlHO FILHO, José dos Santos. Entre o Guardião de Promessas e o Superego da Sociedade: Limites e Possibilidades da jurisdição constitucional no Brasil. In: XIMENES, Julia Maurmann (org.). Judicialização da Política e Democracia. Brasília: IDP, 2014.

CAVAZANNI, Ricardo Duarte. Crise da Democracia Representativa e os reflexos sobre a separação dos poderes: o enfraquecimento do Estado. Constituição, Economia e Desenvolvimento. Revista da Academia Brasileira de Direito Constitucional, Curitiba, vol. 6, n. 11, jul./dez, 2014. CLÈVE, Clèmerson Merlin; LORENZETTO, Bruno Meneses. Diálogos Institucionais: estrutura e legitimidade. Doutrinas Essenciais de Direito Constitucional. Vol. 7/2015, p. 395-421, ago, 2015.

FONSECA, Cláudia de Oliveira. O ativismo judicial e a prática dos diálogos institucionais no âmbito da concretização do direito à saúde. 2014. 137 f.; Dissertação (mestrado) - Universidade de Brasília. Brasília, 2014. 
FRANCISCO, José Carlos. Poder Executivo e Presidencialismo - Art. 76. In: J.J. Gomes Canotilho; Gilmar Ferreira Mendes; Ingo Wolfgang Sarlet; Lenio Luiz Streck; Léo Ferreira Leoncy. (Org.). Comentários à Constituição do Brasil. $2^{a}$ ed.São Paulo: Editora Saraiva, 2018, v. 1, p. $1265-1278$.

FRANCISCO, José Carlos. (Neo) Constitucionalismo na pós-modernidade: princípios fundamentais e justiça pluralista. In: José Carlos Francisco. (Org.). Neoconstitucionalismo e atividade jurisdicional: do passivismo ao ativismo judicial. 1 a ed.Belo Horizonte/MG: Editora Del Rey, 2012, v. 1 , p. $47-88$.

GARGARELLA, Roberto. Latin american constitucionalismo, 18102010: the engine room of the Constitution. Nova York: Oxford University Press, 2013.

GUNDIM, Wagner Wilson Deiró. Recall e Juízo Político: mecanismos de combate às crises de representação no Brasil. São Paulo: LiberArs, 2018. GUTMANN, Amy, e THOMPSON, Dennis. Why Deliberative Democracy?, New Jersey: Princeton University Press, 2004.

HÄBERLE, Peter. Hermenêutica constitucional a sociedade aberta dos intérpretes da Constituição: contribuição para a interpretação pluralista e "procedimental" da Constituição. Trad. Gilmar Ferreira Mendes. Porto Alegre: Sergio Antonio Fabris, 1997.

HERNÁNDEZ, Antonio. A Tres Lustros de la Reforma Constitucional de 1994. Revista de la Faculdad de Derecho de México, vol. 60, 254, 2010.

KLARE, Karl E. Legal Culture and Transformative Constitucionalism. South African Journal on Human Rights, vol 14 (1), 1998.

KLARMAN, Michael. Courts, Social Change, and Political Backlash. In: Hart Lecture at Georgetown Law Center, March 31, 2011 - Speaker's Notes, disponível em http://tinyurl.com/bz4cwqk. Acesso em: 28 nov 2018. LACERDA, André Reis. Separação Dinâmica das funções estatais: análise de um ativismo judicial moderado na perspectiva de uma leitura dialógica da Constituição Brasileira de 1988 - Impediente de Configuração de Instâncias Hegemônicas. RIDB, no 6, Ano 2, p. 5045-5108, 2013, p. 5085. Disponível em: http://www.cidp.pt/publicacoes/revistas/ridb/2013/06/20 13_06_05045_05108.pdf. Acesso em: 12 abr. 2016. 
LEDERACH, John Paul. Transformação de conflitos. São Paulo: Palas Athena, 2012.

LORENCINI, Bruno César; GUNDIM, Wagner Wilson Deiró. O recall e sua viabilidade como solução ao Brasil. Revista da Faculdade de Direito do Sul de Minas, Pouso Alegre, v. 33, n. 1: 373-406, jan./jun. 2017.

LORENCINI, Bruno César. Democracia e responsabilidade política. Barcelona: Erasmus, 2015.

MENEZES, Flavia Ferreira Jacó; SILVA, Alexandre Garrido. Poder Judiciário e diálogos institucionais: uma perspectiva frente à flexibilização das decisões. Revista Horizonte Científico, Vol. 8, n 1, Jul -2014. Disponível em: <http://www.seer.ufu.br/index.php/horizontecientifico/article/ view/17921/14854>. Acesso em 06 Jul. 2016.

MIRANDA, Danilo Nunes Cronemberger. Constitucionalismo e Diálogo Institucional: uma análise dos limites pragmáticos e normativos da noção de ativismo judicial. In: BUSTAMANTE, Thomas; FERNANDES, Bernardo Gonçalves; SAMPAIO, José Adércio Leite; REZENDE, ÉLCIO NACUR; MOREIRA, Ana Luísa Navarro; MARTINS, João Víctor Nascimento; ENRÍQUEZ, Igor de Carvalho (orgs.). Entre a Crítica e a Defesa da Legitimidade da Jurisdição Constitucional. Anais do I Congresso Internacional de Direito Constitucional e Filosofia Política. $1^{\text {a }}$ ed., p. 56-68, Belo Horizonte: Initia Via, 2015.

NETO, João Costa. A Corte Constitucional sul-africana e os direitos fundamentais: um paradigma a ser seguido? Observatório da Jurisdição Constitucional. Ano 7, n. 1, jan./jun. 2014.

PAUMGARTTEN, Michele Pedrosa. Constitucionalismo transformador: o caso sul-africano. Rev.SJRJ, Rio de Janeiro, v. 34, p. 147-161, ago. 2012.

PRANIS, Kay. Processos Circulares. São Paulo: Palas Athena, 2010.

SANTOS, Luiz Alberto. PECs que buscam instituir o parlamentarismo são inconstitucionais. Consultor Jurídico. Disponível em: https://www. conjur.com.br/2016-mar-28/luiz-santos-pecs-propoe-parlamentarismo-sao-inconstitucionais. Acesso em: 02 jan. 2018.

SCHAFER, Jack e KARLINS, Marvin. Manual de Persuasão do FBI. São Paulo: Universo dos Livros, 2015. 
SILVA, Cecília de Almeida; MOURA, Francisco; BERMAN, José Guilherme; VIEIRA, José Ribas; TAVARES, Rodrigo de Souza; VALLE, Vanice Regina Lírio. Diálogos institucionais e ativismo. Curitiba: Juruá, 2012. TUSHNET, Mark. Weak Courts, Strong Rights: Judicial Review and Social Welfare Rights in Comparative Constitucional Law. Princeton: Princeton University Press, 2008.

\section{GIANFRANCO FAGGIN MASTRO ANDRÉA}

Doutorando e Mestre em Direito Político e Econômico pela Universidade Presbiteriana Mackenzie. Especialista em Direito Público pela Faculdade de Direito Damásio de Jesus. Bacharel em Direito pela Universidade Presbiteriana Mackenzie. Membro do Grupo de Pesquisa Cidadania, Constituição e Estado Democrático de Direito da mesma Universidade. Docente na Faculdade de Direito da Universidade Paulista. Analista do Ministério Público da União.

Endereço Profissional: Av. Brigadeiro Luís Antônio, 2020 - Bela Vista - São Paulo - Capital. CEP: 01317-000, Brasil.

ORCID ID: http://orcid.org/0000-0003-4817-0298

E-mAIL: gfaggin@gmail.com

\section{JOSÉ CARLOS FRANCISCO}

Graduação em Direito pela Universidade de São Paulo (1987); Mestrado em Direito pela Universidade de São Paulo (1998); Doutorado em Direito pela Universidade de São Paulo (2003); Professor da Universidade Presbiteriana Mackenzie (graduação, mestrado e doutorado); Membro do Instituto Pimenta Bueno - Associação Brasileira dos Constitucionalistas; Associado-dirigente do Instituto Brasileiro de Estudos Constitucionais - IBEC; Diretor do Centro de Estudos da AJUFESP - Associação dos Juízes Federais de São 
Paulo e do Mato Grosso do Sul (de 2013 até 2019); Desembargador

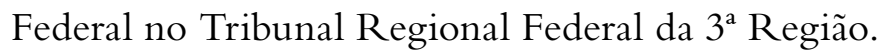

Endereço Profissional: Av. Paulista, 1842 - Bela Vista, São Paulo SP, 01310-936, Brasil.

ORCID ID: https://orcid.org/0000-0002-2512-0098

E-MAIL: jcarlosfrancisco@hotmail.com

\section{WAGNER WILSON DEIRÓ GUNDIM}

Pós-Doutorado em Direito e Novas Tecnologias pela Mediterranea International Centre for Human Rights Research, em parceria com a Università Mediterranea di Reggio Calabria - Itália (2020-2021), com bolsa integral. Doutor em Filosofia do Direito pela Pontifícia Universidade Católica de São Paulo, tendo sido bolsista CAPES. Doutorando em Direito Constitucional pela Faculdade de Direito da Universidade de São Paulo (FADUSP). Mestre em Direito Político e Econômico pela Universidade Presbiteriana Mackenzie. Professor de Direito Constitucional, Eleitoral, Ciência Política e Teoria do Estado da Faculdade de Direito da Universidade Anhembi Morumbi. Sócio fundador do Gundim \& Ganzella Sociedade de Advogados. Endereço Profissional: Avenida Paulista, n. ${ }^{\circ}$ 2073, Horsa I, Cj. 1214. Bela Vista. São Paulo / SP. CEP: 01311-300, Brasil.

ORCID ID: http://orcid.org/0000-0003-4309-2788

E-MAIL: wagner.gundim@adv.oabsp.org.br

Recebido: $10 / 06 / 2020$

Aceito: $10 / 09 / 2020$ 


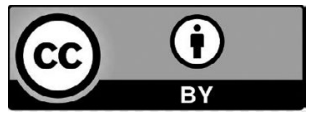

Este trabalho está licenciado sob uma licença Creative Commons Attribution 4.0 International License.

Autores e autoras cedem à Revista Sequência direitos exclusivos de primeira publicação, ficando o trabalho licenciado sob a Creative Commons Attribution 4.0 International License. A licença autoriza que terceiros remixem, adaptem e ou criem a partir do trabalho publicado, indicando o crédito ao trabalho original e sua publicação inicial. Os autores têm permissão para assumir contratos adicionais em separado, com distribuição não exclusiva da versão publicada na Revista Sequência, indicando, de todo modo, a autoria e publicação inicial neste periódico. 